\title{
EFEITOS FÍSICOS E SIMBÓLICO-CULTURAIS NA PRODUÇÃO DE RENDA DE BILRO: UM LEVANTAMENTO BIBLIOMÉTRICO
}

\section{PHYSICALAND SYMBOLIC-CULTURAL EFFECTS ON BOBBIN LACE PRODUCTION: A BIBLIOMETRICH RESEARCH}

\author{
Rosielli de Sá e Silva ${ }^{1}$, Esp. \\ Milton Cinelli², D.Sc. \\ (1) UDESC \\ e-mail: rosiellisa@gmail.com
}

(2) UDESC

e-mail: Milton.cinelli@udesc.br

Renda de Bilro, Ergonomia, Trabalho artesanal

O estudo apresenta os principais fatores que influenciam no trabalho com renda de bilro a fim de determinar os efeitos físicos e simbólico-culturais da sua produção. Com isso, verificou-se a dualidade entre o prazer no fazer a renda e a sua repercussão sobre a qualidade de vida no trabalho da rendeira.

\section{Bobbin Lace, Ergonomics, Craftwork}

The study presents the main factors that influences in bobbin lace work, in order to determine the physical and symbolic-cultural effects of its production. With this, the duality between the pleasure on making the lace and its repercussion on worker's life quality was verified.

\section{Introdução}

A atividade artesanal, atualmente, está relacionada com os valores tangíveis e intangíveis da sociedade. Possui características de manufatura, com utilização de métodos tradicionais ou rudimentares, ao mesmo tempo em que envolve criatividade, domínio da técnica e do processo de produção e identificação cultural com o local de ofício (BARROS, 2006).

Essa sinergia entre a produção e o agente modificador, por sua vez, converte-se em fatores que afetam o artesão e o produto. $\mathrm{O}$ ambiente e as condições de trabalho, nesse contexto, são feitos de modo informal, com instrumentos tradicionais, que nem sempre levam em consideração os Fatores 


\section{$16^{\circ}$ \\ ERGODESIGN USIHC CINAHPA}

$16^{\circ}$ Ergodesign - Congresso Internacional de Ergonomia e Usabilidade de Interfaces Humano Tecnológica: Produto, Informações Ambientes Construídos e Transporte

$16^{\circ}$ USIHC - Congresso Internacional de Ergonomia e Usabilidade de Interfaces Humano Computador

CINAHPA | 2017 - Congresso Internacional de Ambientes Hipermídia para Aprendizagem.
Humanos no processo de desenvolvimento, levando as pessoas a se adaptarem ao seu posto de trabalho, ao invés de ser o contrário (CHIM J. , 2014).

Posturas constrangedoras, condições insalubres de trabalho e ferramentas inadequadas, são algumas das circunstâncias que levam o trabalhador a apresentar quadro de dores, lesões e desconfortos musculoesqueléticos (KUMAR, 2007).

Desse modo, a produção da renda de bilro também é relatada nessa perspectiva de intimidade e reciprocidade com a técnica, na qual o resultado do trabalho é espectro das condições de trabalho e da artesã.

Com isso, o artigo apresenta uma revisão dos principais aspectos que influenciam no trabalho com renda de bilro a fim de determinar: 1) os efeitos das transformações simbólico-culturais na produção de renda de bilro; e 2) os efeitos físicos da atividade que impactam na saúde e qualidade de vida das rendeiras.

\section{Metodologia}

A coleta de dados para o artigo foi realizada com base em uma revisão de literatura das bases de dados da Capes, que indexa resultados de fontes como Science Direct e Scielo; Google Scholar, Scopus e BDTD (Biblioteca Digital Brasileira de Teses e Dissertações). As palavras-chave utilizadas foram "renda + bilro" e "ergonomia" e suas correspondentes em inglês "bobbin + lace", "ergonomics" e "human factors". Os critérios de inclusão foram a coerência ao tema e artigos revisados por pares, e de exclusão artigos semelhantes entres si. Sendo que o período de busca não foi restringido para que abrangesse uma quantidade maior de dados.

Ao total foram encontrados 126 artigos e 15 dissertações e selecionados 18 trabalhos, dos quais 9 são artigos publicados em periódicos e 9 dissertações, durante o período de 2000 a 2015.

\section{Resultados e Discussão \\ 3.1 Efeitos simbólico-culturais da Renda de Bilro}

A renda de bilro, por ser uma atividade artesanal, permite a sua adaptação conforme as singularidades de quem o faz. Nesse âmbito, preferências sobre os equipamentos, métodos de produção, e particularidades na forma de aprendizagem irão influenciar no resultado final da renda, o que contribui para a sua caracterização e diferenciação.

Enquanto atividade, a renda passou por transformações em seu propósito e manufatura. Historicamente vista como função feminina, tinha caráter de entretenimento e integrava o rol das prendas domésticas ensinadas às meninas por volta dos 6 a 7 anos de idade (ZANELLA, BALBINOT, \& PEREIRA, 2000). No entanto, a difusão da técnica e mudanças no contexto social e econômico impulsionaram sua transição para o contexto comercial de produção. Ou seja, de produção para igrejas e ornamentação da casa, passou a representar fonte de subsídio como complemento do orçamento familiar (ZANELLA, BALBINOT, \& PEREIRA, 2008), (BERGAMIM, 2013), (ANGELO, 2013).

Assim, de entretenimento e aspecto regulador da conduta feminina, passa a ser instrumento de subsistência e fomentador da independência financeira (ZANELLA, BALBINOT, \& PEREIRA, 2000), (BERGAMIM, 2013). O ensino da renda, portanto, era intercalado com a escola, quando permitido pelas famílias, e as tarefas domésticas. A retirada de alguns pontos, nesse sentido, simplificou o aprendizado, e também acelerava a produção. Com o dinheiro obtido das vendas era possível colaborar com o sustento familiar e também comprar itens de uso pessoal, como artigos do vestuário.

Atualmente, com a globalização e novos cenários de trabalho, não há mais essa obrigação pela aprendizagem e produção da renda, o que impacta na transmissão do conhecimento, que inicialmente era feito de forma tradicional, passado de mãe para filha. Essa situação aliada à baixa remuneração impacta na difusão e perpetuidade da técnica, uma vez que o trabalho com renda geralmente não é atrativo economicamente para as novas gerações
Realização:

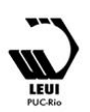




\section{$16^{\circ}$ \\ ERGODESIGN USIHC CINAHPA}

$16^{\circ}$ Ergodesign - Congresso Internacional de Ergonomia e Usabilidade de Interfaces Humano Tecnológica: Produto, Informações Ambientes Construídos e Transporte

$16^{\circ}$ USIHC - Congresso Internacional de Ergonomia e Usabilidade de Interfaces Humano Computador

CINAHPA | 2017 - Congresso Internacional de Ambientes Hipermídia para Aprendizagem.
(BRUSSI, 2009).

As rendeiras que atuam na profissão, no entanto, organizam-se de forma independente ou coletiva, dentro de cooperativas, e tem autonomia no seu processo produtivo, intercalando as atividades com tarefas domésticas e pessoais (BARROS K. , 2009)(CORDEIRO, 2011).

Atualmente, entretanto, a demanda na produção e o tempo para execução de cada peça, resultaram em transformações no aspecto produtivo, que contribuem para decair a qualidade da renda ou se perder a representação de rendas antigas. Com isso, alguns aspectos característicos da renda, como o desenho do pique, foram alterados para que contenham menos pares de bilros, e consequentemente, agilizar a produção (ALMEIDA J. , 2010), (SALDANHA \& ALMEIDA, 2015).

Brussi (2009) também apresenta essa situação, porém observada no contexto cearense de produção da renda de bilro, nas praias de Alto Alegre e Prainha. Lá, e também em outros lugares em que se tece a renda de bilro, ocorre o fenômeno da renda "roubada". Essa denominação é em decorrência das artesãs não seguirem todos os pontos necessários para a confecção do desenho no pique, omitindo pontos e bilros, e por isso diz-se que "roubando" a renda. Ou então, substituindo pontos complexos por outros mais simples (BRUSSI, 2009). Como resultado, a renda fica mole, larga, com buracos ao invés de padrões, e com menor tempo de produção e custo, uma vez que a quantidade de linha empregada também é reduzida.

Além disso, outro fator que contribui para a queda na qualidade da renda é a espessura da linha utilizada. Muitas rendeiras preferem usar a linha com espessura mais grossa, a fim de preencher os padrões do molde com menos pontos, acelerando a produção e reduzindo os custos. Porém, o resultado implica em uma renda com aspecto mais rústico e menos delicado do que com linhas mais finas.

Essas transformações, por sua vez, também provocaram ressignificações no fazer a renda que a situam no contexto contemporâneo de mercado. Variações nos piques e introdução de novas cores e materiais resultam em peças diferenciadas que compreendem artigos do vestuário e de decoração. Assim, ocorrem variações de estilo, com interpretações próprias dos pontos e desenhos tradicionais (ALMEIDA, MENDES, \& HELD, 2011).

O domínio da técnica, portanto, possibilita a expansão de alternativas no uso da renda de bilro, que por sua vez, ressignificam a sua produção bem como auxiliam a situa-la no mercado.

\subsection{Os efeitos físicos da atividade}

Por mais que a renda de bilro forneça aspectos de satisfação, bem-estar e auto-estima no trabalho, ela também imprime efeitos físicos sobre o corpo e a saúde da rendeira (PITTA, 2010). Os equipamentos são de ordem artesanal e não são projetados ergonomicamente. Com isso, os Fatores Humanos não são considerados, trazendo consequências a curto e longo prazo sobre a qualidade de vida das artesãs.

Nessa perspectiva, as rendeiras das comunidades apresentadas pelos estudos demonstraram limitações físicas nos joelhos, coluna e visão (PITTA, 2010.); (BARROS K. , 2009); (SALDANHA M. e., 2007). Essa situação é decorrente entre outros motivos, do trabalho feito no chão, com suportes e assentos inadequados e iluminação insuficiente para a atividade.

Assim, o constrangimento postural advindo de anos de trabalho provoca dores, desconforto e lesões musculoesqueléticas (SALDANHA M. e., 2007). Com relação à visão, essa foi prejudicada pelo uso da lamparina como fonte de iluminação quando não se tinha acesso à energia elétrica, e também da baixa luminosidade do local de trabalho (BECK, 1983). Outra dificuldade observada é com relação às linhas aplicadas na confecção das peças. As tradicionais branca e bege não apresentam problemas, no entanto algumas rendeiras em razão do avanço da idade, têm dificuldade para tecer com linhas coloridas como vermelha e preta, pois relatam que atrapalha a
Realização:

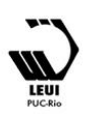




\section{$16^{\circ}$ \\ ERGODESIGN USIHC CINAHPA}

$16^{\circ}$ Ergodesign - Congresso Internacional de Ergonomia e Usabilidade de Interfaces Humano Tecnológica: Produto, Informações Ambientes Construídos e Transporte

$16^{\circ}$ USIHC - Congresso Internacional de Ergonomia e Usabilidade de Interfaces Humano Computador

CINAHPA | 2017 - Congresso Internacional de Ambientes Hipermídia para Aprendizagem.
visão(ALMEIDA A. , 2014).

Beck et.al (1983), nessa perspectiva, aponta que o trabalho com renda é uma atividade que desgasta fisicamente a artesã de forma lenta e gradativa. Em depoimentos coletados em Florianópolis, observou-se que os distúrbios na visão começam por volta dos 40 anos de idade. Com isso, a rendeira elimina o trabalho noturno, depois as linhas de cores escuras, e quando chega aos 60,70 anos de idade geralmente deixa de fazer a renda, ou a faz com limitações, nem sempre resultando em um trabalho de qualidade (WENDHAUSEN \& MACHADO, 2016).

Em decorrência desses aspectos, alguns estudos realizam uma análise ergonômica do trabalho com renda de bilro, a fim de avaliar as condições físicas, psicológicas e organizacionais no qual a atividade está inserida.

Saldanha et.al (2007) realiza uma pesquisa com as rendeiras da Vila de Ponta Negra, em Natal (RN), no sentido de averiguar os motivos pelos quais um grupo de rendeiras na faixa etária acima dos 50 anos e com mais de 30 anos de profissão apresentavam baixa ocorrência de adoecimento por LER/DORT (Lesão por Esforço Repetitivo/ Distúrbios Osteomusculares Relacionados ao Trabalho), embora o trabalho envolva alta taxa de repetitividade e velocidade na movimentação de mãos e dedos.

Observou-se a precariedade do posto de trabalho, com baixa luminosidade e ventilação, o que leva as rendeiras a se posicionarem perto da porta onde há maior incidência de luz natural. Além disso, o suporte é fixo e sem espaço para movimentação das pernas e o assento é inadequado. Essa situação repercute em dores e desconfortos, principalmente na região dorsal, que são amenizados pelas pausas realizadas ao longo da jornada (SALDANHA M. e., 2007).

Com relação à movimentação dos bilros, observouse que para o mesmo tipo de trama podem existir diferentes tipos de manejo, sendo que o envolvimento dos membros é diferenciado de acordo com os pontos a serem executados.
No que tange à contagem de movimentos, observou-se que a atividade supera a quantidade de dez mil manipulações por hora, o que ultrapassa o limite máximo de movimentos de pressão digital, regido pela Norma Regulamentadora NR 17, que prevê no máximo oito mil toques por hora como medida de segurança. Mesmo com essa situação, não foram encontrados registros de LER/DORT nas rendeiras em função da atividade. Isso se deve ao domínio do processo pela artesã, que pode estipular as pausas necessárias durante o trabalho, além dos fatores psicológicos de convivência em grupo e sociabilidade, que contribuem na prevenção às doenças musculoesqueléticas, uma vez que o estado de estresse e tensão é minimizado (SALDANHA M. e., 2007).

Em detrimento a essa situação, Pitta (2010), ao realizar uma pesquisa com as rendeiras de Aquiraz (CE), encontrou registros de dores nos punhos em razão do trabalho manual repetitivo, o que pode desencadear quadros de LER/DORT. A autora também constata que se por um lado a atividade da renda traz sensação de prazer e bem-estar, por outro, a postura adotada para a prática "estimula dores lombares, cervicais, desgaste das articulações proximais e distais nos membros superiores, dentre outros (PITTA, 2010., p. 53).

Wendhausen e Machado (2016), ao entrevistarem as rendeiras de Florianópolis, relatam que principalmente a atividade de enrolar o bilro contribui para essa situação, uma vez que dependendo do tipo de desenho, podem ser utilizados até 30 pares de bilros ou mais (ALMEIDA J. , 2010), o que provoca fadiga muscular e distúrbios musculoesqueléticos, como a síndrome do túnel do carpo (WENDHAUSEN \& MACHADO, 2016).

Nesse contexto, a iluminação natural ao longo do dia se esvanece e provoca a flexão do pescoço e tronco das rendeiras em direção às almofadas, em razão da baixa visibilidade do desenho, o que provoca tensões musculares. Em meio a isso, juntam-se a demanda por destreza manual e concentração no desenvolvimento das tarefas, que envolvem diferentes tipos de operações. 


\section{$16^{\circ}$ \\ ERGODESIGN USIHC CINAHPA}

Assim, os efeitos físicos da atividade ocorrem da conjunção entre fatores ergonômicos da atividade, associados às características genéticas, que com o passar do tempo, acarretam em conseqüências na saúde e qualidade de vida das rendeiras.

\section{Considerações Finais}

O artigo objetivou apresentar uma revisão dos principais aspectos que influenciam no trabalho com renda de bilro a fim de verificar os efeitos das transformações simbólico-culturais na produção e o impacto na saúde e qualidade de vida das rendeiras.

Assim, no que tange à parte simbólico-cultural e social, verificou-se que as mudanças advindas do mercado, e a demanda por produtos repercutiram no modo produtivo da renda, que deveria ficar pronta em menor espaço de tempo. Desse modo, as artesãs desenvolveram estratégias para lidar com essa situação e adaptaram elementos constituintes da renda, ressignificando o seu caráter simbólico e produtivo.

Nesse contexto, ocorre também a dualidade entre o prazer no fazer a renda, e os efeitos físicos da profissão, os quais são advindos por problemas ergonômicos do posto de trabalho e também aspectos genéticos e de idade.

A partir do panorama apresentado, portanto, podem-se realizar estudos a fim de melhorar a ergonomia da atividade, levando-se em consideração os Fatores Humanos no processo de tecer, para que ocorra a perpetuação e difusão da técnica.

\section{BIBLIOGRAFIA}

ALMEIDA, A. (2014). Tecendo investigações sobre rendas: o trocar de bilros no Piaú. Campinas, São Paulo: Dissertação (Mestrado). Universidade Estadual de Campinas. Instituto de Filosofia e Ciências Humanas.

ALMEIDA, A., MENDES, F., \& HELD, M. (2011). A tradição em fazer rendas de bilros: um estudo de caso das rendeiras da Prainha, Aquiraz - $16^{\circ}$ Ergodesign - Congresso Internacional de Ergonomia e Usabilidade de Interfaces Humano Tecnológica: Produto, Informações Ambientes Construídos e Transporte

$16^{\circ}$ USIHC - Congresso Internacional de Ergonomia e Usabilidade de Interfaces Humano Computador

CINAHPA | 2017 - Congresso Internacional de Ambientes Hipermídia para Aprendizagem.

CE. IARA - Revista de Moda, Cultura e Arte., pp. $84-110$.
ALMEIDA, J. (2010). Modelagem situada de metodologia da oficina de desenho de renda de bilros. Natal: Dissertação de Mestrado em Engenharia de Produção. Programa de Pós- Graduação em Engenharia de Produção da Universidade Federal do Rio Grande do Norte (UFRN).

ANGELO, E. (2013). O "saber-fazer" renda de bilros: as ressignificações do processo na Lagoa da Conceição em Florianópolis. Revista de História: História, Sociedade e Cultura, pp. 11 - 27.

\section{BARROS, K. (2009). Análise}

Antropotecnológica do desenvolvimento de novos produtos na produção artesanal: caso das rendeiras de bilro da Vila de Ponta Negra, em Natal - RN. Natal: Dissertação de Mestrado em Engenharia de Produção. Programa de PósGraduação em Engenharia de Produção da Universidade Federal do Rio Grande do Norte (UFRN).

BARROS, L. (2006). Design e Artesanato: as trocas possíveis. Rio de Janeiro: Dissertação de Mestrado em Design. Programa de Pós-Graduação em Design do Departamento de Artes e Design da PUC Rio.

BECK, A. e. (1983). Trabalho limpo: a renda de bilro e a reprodução familiar. Florianópolis.: Universidade Federal de Santa Catarina. Próreitoria de assuntos estudantis e extensão.

BERGAMIM, C. (2013). A importância da renda de bilro na economia familiar em Florianópolis a partir de 1900 e a sua continuidade no tempo presente. Revista Santa Catarina em História., pp. $14-27$.

BRUSSI, J. (2009). Da "renda roubada" à renda exportada: a produção e a comercialização da renda em dois contextos cearenses. Brasília, DF: Dissertação. Mestrado em Antropologia Social. Departamento de Antropologia.

CHIM, J. (2014). The FITS model office
Realização:

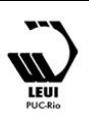




\section{$16^{\circ}$ \\ ERGODESIGN USIHC CINAHPA}

ergonomics program: a model for best practice. Work, pp. 495-501.

\section{CORDEIRO, Â. (2011). Rendeiras da Vila de}

Ponta Negra (Natal/RN): o ensino da renda de bilro e do desenho como alternativa de continuidade da produção artesanal tradicional. Natal: Dissertação de Mestrado em Engenharia de Produção. Programa de Pós-Graduação em Engenharia de Produção da Universidade Federal do Rio Grande do Norte.

KUMAR, S. (2007). Biomechanics in Ergonomics. (S. KUMAR, Ed.) Boca Raton: Taylor \& Francis Group.

PITTA, L. (2010.). Trabalho manual: a técnica da renda de bilro como elemento de promoção da saúde. Fortaleza., Ceará.: Universidade Estadual do Ceará. Dissertação de Mestrado Acadêmico em Saúde Pública. Centro de Ciências da Saúde.

SALDANHA, M. e. (2007). Ocorrência de LER/DORT em rendeiras de bilro do núcleo de produção artesanal de Ponta Negra em Natal/RN: As razões do não-adoecer. XXVIII Encontro Nacional de Engenharia de Produção (ENEGEP).

SALDANHA, M., \& ALMEIDA, J. (2015). Em busca de um saber perdido: contribuição da ergonomia para a concepção da oficina de desenho renda de bilro. Ação Ergonômica, pp. 1 - 9.

WENDHAUSEN, M., \& MACHADO, C. (20 de Abril de 2016). Entrevista com as autoras do livro Renda de Bilro: um legado açoriano em Florianópolis. (R. SÁ, Entrevistador)

ZANELLA, A., BALBINOT, G., \& PEREIRA, R. (2000). A renda que enreda: analisando o processo de constituir-se rendeira. Educação e Sociedade, pp. 235 - 252.

ZANELLA, A., BALBINOT, G., \& PEREIRA, R. (2008). Tu me ensina a fazer renda que eu te ensino a...inovar: um estudo do processo de constituir-se rendeira à luz da psicologia históricocultural. In: A. e. SILVEIRA, Cidadania e participação social. (pp. 168 - 179). Rio de Janeiro: $16^{\circ}$ Ergodesign - Congresso Internacional de Ergonomia e Usabilidade de Interfaces Humano Tecnológica: Produto, Informações Ambientes Construídos e Transporte

$16^{\circ}$ USIHC - Congresso Internacional de Ergonomia e Usabilidade de Interfaces Humano Computador

CINAHPA | 2017 - Congresso Internacional de Ambientes Hipermídia para Aprendizagem.

\section{Agradecimentos}

Agradecemos à Capes que foi responsável pelo financiamento desta pesquisa, ao CNPq, aos professores e coordenação do Programa de Pósgraduação em Design da UDESC, e aos professores e bolsistas do Pós Design UFSC. 